\title{
Notes and Comment
}

\section{A simple demonstration of border dominance in binocular rivalry}

\author{
ARNULF REMOLE \\ School of Optometry \\ University of Waterloo \\ Waterloo, Ontario N2L 3G1, Canada
}

Binocular rivalry is perceived when corresponding areas in the two eyes are presented with markedly different stimuli. The classical target used most frequently to demonstrate this phenomenon consists of closely spaced straight parallel lines, the left and right portions oriented $90 \mathrm{deg}$ to each other. Their perceived binocular synthesis is a patchwork of segments, some from the left stimulus field and some from the right. The fragments from the conflicting stimuli continually alternate in dominating the various portions of the binocularly perceived visual field. At no time are lines seen to cross each other (Ogle, 1962).

Hering (Levelt, 1968) emphasized the supreme importance of contour stimulation in binocular rivalry. If one eye is presented with a uniform field and the other with a contour, the contour is never suppressed by the uniform field. Linksz (1952) pointed out that overlay of contour is the most powerful of all visual clues, be they monocular or binocular. Levelt (1968), in his studies on binocular brightness integration, further stressed the importance of border information in the visual field for the binocular brightness synthesis.

Levelt (1968) performed psychophysical measurements of the binocular brightness resulting from the fusion of identically sized, uniformly luminous circular left and right fields. As the luminance of one field was increased, a complementary reduction was required in the contralateral field to maintain a binocular brightness matching a constant brightness binocular control field of the same shape. However, when a border in the form of a dark annulus was introduced in one of the variable test fields, the reciprocal relationship altered in favor of the stimulus containing the border. Thus, for a given combination of unequally luminous left and right test fields, a border in the more luminous field brought about an increase in the perceived binocular brightness. Conversely, a border placed in the lower luminance field effected a decrease in the binocular brightness. In addition, Levelt demonstrated that the dominating influence of the border on its surround was limited to a finite distance away from this border.

In this report, we present a qualitative demonstration of the dominant effect of a border and its surround in the binocular percept. Figure 1 shows left and right targets that can be fused freely or by means of a suitable steroscope. To the right of the fusion target is shown a typical example of the perceived binocular effect. Since the conflicting backgrounds of the stimuli will give rise to rivalry, the binocular percept can take other forms than that illustrated. Some of the various forms are discussed below.

\section{Observations and Discussion}

The vertical line segments, whether black or white, are always present in the binocular visual field, regardless of the form or stage of the rivalry between the conflicting grounds. This verifies the well-known principle of border dominance referred to above.

During fusion of the circles, the background of the upper target is seen as much brighter than that of the lower target, the middle target showing an intermediate level of perceived brightness. When there is marked rivalry between the grounds, this observation pertains to the mean perceived brightness of the three targets. This shows that the dominance of the border is extended, to some degree, to its surround.

Unlike the constant and supreme dominance of the border, the dominance of its surround is not complete. During the various stages of rivalry, it can extend through the entire encircled area or shrink to the immediate vicinity of the border. In the latter case, the border appears surrounded by a halo, bright
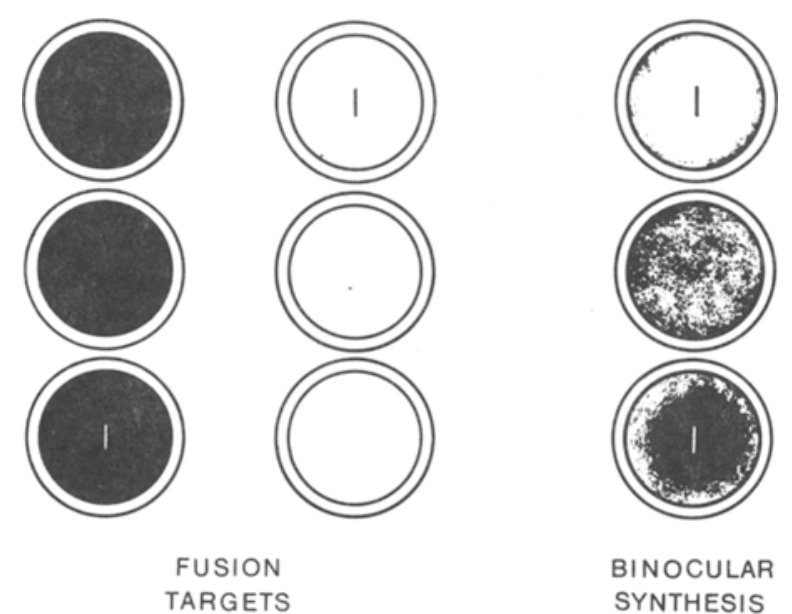

BINOCULAR SYNTHESIS

Figure 1. The three pairs of left and right targets can be fused to produce rivalry between the conflicting grounds. The vertical line segment, presented monocularly, will dominate the binocular visual field as shown to the right. Furthermore, the ground immediately surrounding the line will show partial dominance that decreases with distance away from the line. 
on a dark ground in the upper target and dark on a bright ground in the lower target. However, the perceived border surround, whether it extends maximally or minimally, is always tinged somewhat by the contralateral, suppressed area. Binocular lustre is often observed, which is another indication of a contribution from the suppressed field.

When the effect of the border surround does not fill the whole circle, there is a gradual transition from its maximum effect near the border towards the periphery. This ramp of perceived brightness change is much larger than the familiar Mach effects and can extend over several degrees of visual angle. The effect is therefore quite different from the abrupt suppression of a line by an orthogonally oriented line in the contralateral field.

Levelt's measurements apply to perceived brightness, his test fields always having greater luminance than the background. In our demonstration, the lower pair of targets presents a border surround that is perceived as dark or black rather than as having some level of brightness. The observations show that the dark area around the border behaves in the same way as the bright area around the border in the upper pair of targets. Thus, the principles set out above apply to darkness perception as well as to brightness perception.

In general, our demonstration verifies Levelt's findings that the border and its immediate surround dominates in the binocular synthesis of the visual field. However, it emphasizes that the dominance of the surround, in contrast to that of the border, is partial, fluctuates in strength, and decreases very gradually away from the border.

\section{REFERENCES}

Levelt, W. J. M. On binocular rivalry. The Hague: Mouton, 1968.

Linksz, A. Physiology of the eve (Vol. 2) Vision. New York: Grune and Stratton, 1952.

OgLe, K. N. Ocular dominance and binocular retinal rivalry. In H. Davson (Ed.), The eve (Vol. 4) Visual optics and the optical space sense. New York: Academic Press, 1962.

(Received for publication March 13, 1980; accepted March 17, 1980.) 